\title{
Exploration- and Exploitation-Oriented Marketing Strategies and Sales Growth in Emerging Markets
}

\author{
Omar Rodriguez Vila ${ }^{1}$ - Sundar G. Bharadwaj ${ }^{2} \cdot$ S. Cem Bahadir ${ }^{3}$
}

Published online: 27 August 2015

(C) Springer Science+Business Media New York 2015

\begin{abstract}
Extant marketing literature recognizes unique and varied aspects of marketing in emerging markets (EMs), and in this study, we also argue that significant market-structure changes within many EMs are creating new challenges and opportunities for managers. In particular, we propose that managers must simultaneously implement exploitation and exploration strategies to confront a high degree of dynamism in EMs reflected via changes in retail structures, competitive intensities, and category characteristics. The results from a panel dataset of 15 EMs across Africa, Asia, Europe, and South America find evidence for the critical nature of exploitation strategies aimed at expanding the affordability and availability of existing products. We also find support for the importance of exploration strategies, in the form of innovative product portfolio, as a way to mitigate the effects of changes in market conditions. The results indicate that marketing managers must emphasize ambidextrous marketing strategy in EMs instead of viewing EMs strictly as sources of horizontal growth for established products in developed markets.
\end{abstract}

Keywords Emerging markets · Global marketing · Exploration · Exploitation · Marketing strategy · Innovation · Affordability

Sundar G. Bharadwaj

Sundar@uga.edu

\footnotetext{
Georgia Institute of Technology, Atlanta, GA, USA

University of Georgia, Athens, GA, USA

Ozyegin University, Istanbul, Turkey
}

\section{Introduction}

Financial markets respond constantly to the relative growth of firms; however, sources of growth for multinational corporations (MNCs) have been shifting. Traditionally, they were found primarily in Western and other high-income countries (HICs). Today, MNCs are attempting to identify opportunities for growth in new, underserved, and emerging markets (EMs). According to the International Monetary Fund's report on the World Economic Outlook in 2014, the potential of EM economies has begun to crystallize over the past decade, aided by structural reforms, strong macroeconomic policies, and an unshackling of government controls; this has paved the way for an expansion in consumer markets. Growing urbanization and the growth in purchasing power of consumers have made these markets highly attractive for domestic and multinational firms. Recent evidence in the revenues of US-based MNCs and the resurgence of EM MNCs [20] suggests that EMs are increasingly becoming significant sources of top-line growth. As a result, a study of the effectiveness of HIC marketing strategies in EM conditions is of particular managerial and academic interest.

A first wave of research on this topic explored the perspective of MNCs and how far HIC-based strategies could be extended into EMs. Extant literature has offered valuable insights on the effect of countries' cultural differences and the need to balance standardization and the customization/ localization of marketing strategies [27, 32, 60]. The literature argues that as markets become more homogeneous and customer preferences become similar [42], firms will benefit from the standardization of strategies and programs. Arguments in favor of standardization include both supply- and demandside benefits. On the supply side, when firms standardize their marketing mix, they benefit from economies of scale through lower total R\&D, manufacturing and marketing expenses, and 
quicker product rollout across global markets [40, 53]. On the demand side, globally standardized products are viewed as providing consistent imagery and common brand associations that can enhance perceptions of higher quality [28], prestige, and cosmopolitanism $[17,53]$. On the other hand, customization can overcome a potential loss of local market relevance induced by standardization $[27,48]$ and may be required by certain commercial regulations, trade restrictions, or differences in market infrastructure [33].

Consistent with the goals of standardization, the entry of MNCs into EMs often targets small but affluent segments of consumers who may, in many respects, resemble consumers in HICs and require few adaptations of strategies or product offerings. However, as major policy changes are creating viable markets in lower socioeconomic segments, firms are beginning to find these markets to be economically viable and are focusing on a new set of consumers by attempting to develop more customized marketing strategies [22]; this requires a greater understanding of the unique nature of market conditions in EMs.

We draw on a novel dataset from a multinational manufacturing firm in the consumer products industry to study how differences in market structure affect firm growth potential in EMs and the role of exploration and exploitation strategies in moderating the effect of EM conditions on top-line growth. Research to date has proposed that marketing in EMs calls for a different set of methods and orientations vs. those practiced in developed markets [50]. To understand the nature of EM conditions, scholars have done extensive research on consumer and culturallevel differences across countries. These studies have been used to explain the need for strategic flexibility when competing in and across EMs [4]. While individual cultural differences are an important consideration, market-level dynamics also influence MNCs' marketing strategies in EMs; however, they have received less attention. To that end, in this study, we focus on the effect of changes in market structure on firm top-line performance. We define market structure as a set of factors that define category, retail, and competitive environments within a given market. While a market structure can have a profound impact across all markets, EMs face a unique set of conditions. First, in terms of retail structure, the growth of urbanization and middle classes has propelled the development of modern retail trade; this has created shifts in transactions for consumer goods away from independent and locally embedded traditional stores toward retail chains offering benefits comparable to those in developed markets [14]. This transformation from small and fragmented to large and consolidated store formats represents a unique challenge in terms of supply chain, distribution, and sales force management for manufacturers attempting to sustain presence across an increasingly diverse set of channel options.
Second, while the retail structure in EMs is shifting toward more consolidated environments, the competitive structure is often evolving in the opposite direction in that many MNCs are experiencing greater and stronger competition from local and regional firms in EMs [20]. For instance, limited intellectual property regulations sometimes enable local competitors to rapidly reproduce less expensive products with similar functional characteristics to the MNCs offerings. Such patterns of competition are often reinforced by the strong community and government affiliations of local firms and a greater speed to market vs. traditional MNCs. As a result, the competitive structure in EMs is intensifying and diversifying.

Finally, in terms of category structure, the accelerated economic development in emerging countries has also enabled large segments of the population to enter the market economy and become consumers of goods. This change is stimulating greater innovation and instigating a transition from more centralized category definitions associated with a few leading products toward greater category segmentation. For instance, in the beverage industry, EMs were often dominated by a few defining categories (e.g., tea, soft drinks, and water); however, those markets are now transitioning into more diverse category structures along traditional lines (e.g., dairy, juice, coffee, and related products).

As a result, many MNCs in EMs face a dynamic and hypercompetitive market structure composed of simultaneous evolutions in retail categories and competitive conditions. We attempt to contribute to the literature on EMs by studying how such dynamism in market structure affects firm performance. Critically, we propose that MNCs need to simultaneously pursue investments in exploration and exploitation as part of their strategies for converting the dynamism of EMs into competitive advantages. This study contributes to an understanding of the moderating role of ambidextrous marketing strategic actions (e.g., exploration and exploitation) on the effects of EM conditions associated with organic growth. We test the hypotheses using a panel dataset in $15 \mathrm{EMs}$ representing Africa, Asia, Europe, and South America and find, after controlling for macro-economic conditions, that the growth in modern retail trade, the dynamism in product categories, and competitive intensity constrain firm performance as measured by sales growth. However, both exploration and exploitation strategies moderate the impact of these structural conditions on sales growth.

The rest of the paper is organized as follows. We first provide an overview of relevant literature and motivate the research question in the study. We then describe the hypotheses relative to the effect of the impact of market structure and firm action on sales growth. Given the prior support in the literature for these relationships, the main effect hypotheses are brief and primarily serve as a foundation for developing the marketing strategy moderator hypotheses. The empirical section outlines the measures and estimation methods used to test the 
hypotheses. The paper concludes with a summary of the findings, description of limitations, and implications for MNCs marketing strategy in EMs.

\section{Theoretical Background}

The impact of business environments on firm performance has been discussed extensively across strategic management, marketing, and organizational theory literature $[2,7,8,44]$. Industry structure and environmental dynamism have been identified as two key environmental factors that affect business environments. While industry structure refers to the relatively stable economic and technical dimensions of an industry that provide the context in which businesses compete with each other [5], dynamism is the amount of uncertainty emanating from an external environment [6]. Highly competitive and dynamic markets put significant constraints on firms' abilities to achieve higher levels of performance. Firms can adopt strategic options, either current or new, to withstand the pressures caused by competition and environmental dynamism. They can explore new market opportunities using new product offerings or exploit their existing products and services [51]. We develop a conceptual model to study the interplay between market structure and MNCs' strategies in an EM context. We identify market structure dynamics that differ from subjective environmental dynamism measures, along with specific strategies that firms may utilize to deal with these dynamics.

\subsection{Market Structure and Marketing Strategy in Emerging Markets}

The study of marketing in EMs has a long history but lacks the depth and breadth of the marketing literature associated with HIC environments. Initial EM studies focused on understanding how strategies in HICs translated to EMs. Such studies, often exploring questions on branding and advertising, often alluded to the importance of cultural variation when explaining differing performance effects of brands across countries. For instance, extant research shows that consumers in some EMs assign greater importance to tangible product attributes such as product price, functionality, and safety $[9,50]$. However, cultural dissimilarities are only one of the key factors to consider when evaluating marketing strategy effects in an EM context. As outlined by Burgess and Steenkamp [9], socioeconomic and regulatory differences also play important roles in shaping the operating conditions of firms in EMs. Socioeconomic differences such as education, employment, and income can have direct effects on the need of firms to adjust marketing strategies in EMs. At the same time, regulatory differences, particularly from consequences of the limitations in the enforcement of the rule of law, the protection of intellectual property, unreliable tax contributions, and obedience to regulations, can lead MNCs to face uneven competitive playing fields despite having assets, which may represent an advantage of marketing in HICs.

Recent studies have reflected on the approach in the literature toward the study of EMs and found it to be lacking in capturing the variety of characteristics of EMs. Most studies seem to be based on Western-first views of the markets and focus on comparing and contrasting how HIC strategies may or may not work in EM conditions [50]. Thus, there is a need to research EM dynamics, based on their own merits, to enhance the understanding of how firms can best compete in EM market conditions instead of simply comparing how such strategies or conditions may vary from HICs. Furthermore, there is a growing demand for information on EMs in the context of identifying new sources of innovation and opportunities to enhance business models and management techniques outside of HIC markets [23].

Different characteristics have been proposed to help scholars understand the unique conditions present in EMs. Sheth [50] proposed inadequate infrastructure, market heterogeneity, sociopolitical governance, unbranded competition, and a chronic shortage of resources as conditions shaping the competitive and market realities of firms in EMs. Most recently, Bahadir et al. [4] use market heterogeneity, unbranded competition, resource and infrastructure availability, and sociopolitical governance as country-market characteristics that distinguish between developed and emerging countries; they also investigate the moderating role on the relationship between elements of the marketing mix and brand sales. While such categorizations are comprehensive and reflect the unique nature of EM conditions, they do not speak to the degree of change and evolution present in many EMs, which is, at times, transformative in nature. In addition, the effort to describe generalizable EM conditions has also led scholars to pay less attention to changes occurring in market structures composed of category, competitive, and retail structures. As clarified in earlier research, EM market structure has often been defined by concentrations of offerings and fragmentations in distribution; this has meant that few product varieties representing a small set of MNCs were distributed via an often informal web of traditional retailers. However, this type of general stereotype is disappearing and a rapid evolution is taking place. In some EMs, the market structure is changing in a simultaneous fashion with (a) retail structure shifting toward modern trade options (e.g., supermarkets and hypermarkets), (b) policy changes that are allowing an expansion of competition and a reduction in the monopoly position of incumbent manufacturers, and (c) support of entry of local firms and an acceleration of competitive intensity [39, 58]. Finally, category structures and associated product varieties are also undergoing rapid changes and affect firm growth $[3,18]$. The extant literature has significantly advanced the understanding of associated EM characteristics; however, literature streams have rarely intersected and have not studied these dynamics over time. 
Firms can employ different marketing strategies to deal with the challenges posed by dynamic EMs. In this study, we adopt the exploration and exploitation framework, which is used to describe different learning and adaption processes available to firms [34] and was originally conceived as a framework to describe organizational learning. The elements serve to describe the choices and trade-offs faced by managers when they create strategies to compete in EMs.

A strategy focused on exploration can enable firms to compete in dynamic environments via an emphasis on search for new ideas, risk taking, experimentation, flexibility, and innovation $[24,34]$. Exploration strategies include entering adjacent product categories with a "new to the company" product or brand. EMs experience dynamic retail and category structures; this can translate into a need for adaptation of firms' products or practices via greater exploration. We submit that an incumbent firm can transform changing market dynamics into new growth opportunities if it establishes a consistent flow of new products, designed to respond to changing market needs; however, while a focus on exploration can lead to superior long-term performance by allowing organizations to enter new market opportunities, it can also divert resources away from more immediate needs. This can inhibit a firm's ability to generate short-term gains [30].

An exploitation strategy is present when firms opt to design marketing activities to extract greater rent out of existing products and market presences instead of entering new markets. By not having to incur the development and research costs of exploring new market offerings, an exploitation strategy can lead to faster market responses and greater abilities to leverage short-term opportunities. Also, an exploitation strategy enables firms to build and maintain competitive positions by leveraging changes in retail structures to increase the availabilities of current products. These product expansion strategies have been found to contribute to firm growth, particularly in the presence of financial resource slack (e.g., [38]). However, exclusively following an exploitation strategy in a dynamic EM context can hinder a firm's ability to grow over time. Thus, companies must contemplate clear trade-offs when determining investment levels for exploration and exploitation marketing strategies in EM contexts. They can invest in deepening the presence and penetration of their current offerings or in evolving their portfolios in light of market changes. In the next section, we consider the effect of market structure dynamism on the likely sales outcome of each choice.

\section{Hypotheses}

\subsection{Main Effects}

The primary focus of our study is on examining the effects of changes in market structure, within an EM, on firm performance and on the ability of firms to confront such changes via market exploration and exploitation strategies. The initial main effect hypothesis relates the impact of changes in market structure to firm performance. For incumbent firms, the dynamic nature of the market structure in EM conditions is expected to have a negative effect on performance; the theoretical explanation is associated with the importance of social embedding in EM conditions. The extant literature indicates that EMs have fewer established rules and regulations governing market behaviors. Thus, the behaviors and, to some extent, performance of firms are often influenced by their networks and social connectedness in given markets.

The development of modern retail trade introduces competition in a more organized fashion. Retailers with expanded outlets and shelf space require a greater number of products in each category, which can reduce barriers to entry for new entrants and enhance competition. Retailers also tend to increase their number of offerings as a means of gaining bargaining power with more dominant manufacturers; this can create opportunities for new product types and categories. Furthermore, modern trade retailers also tend to introduce store brands [31]. Thus, the growth in share of modern retail is expected to curtail the growth of branded manufacturers' sales [37].

New offerings, in specific markets, also lead to greater dynamism in category structures defined as the share of product segments that generate the majority of sales and consumption within a category. Dynamic changes in category structure tend to provide consumers with more choices and potentially equally attractive options. A significant body of research in psychology finds that when faced with such situations, consumers are likely to delay consumption as a result of choicemaking conflicts, which can reduce the intrinsic motivation to commit to a purchase (e.g., [25, 26, 49]). Consistent with these results from experimental research, a meta-analysis of organic growth finds that dynamism in markets attenuates organic growth [3].

An increase in the competitive intensity within a product category tends to promote a growing number of competing options, cause a decline in differentiation, and ultimately create a climate for firms to compete on price $[12,15,16]$. Consistent with this expectation, the meta-analysis on firm growth finds that competitive intensity has a significant negative impact on growth [3]. As a result, we expect that in EMs,

H1a. The greater the share of modern retail trade, the lower the sales growth of the incumbent firm.

H1b. The greater the dynamism of changes in category structure, the lower the sales growth of the incumbent firm.

H1c. The greater the competitive intensity in the category, the lower the sales of the incumbent firm. 


\subsection{Moderator Hypotheses}

Despite the potential for firm growth performance to be negatively affected by changes in market structure [57], marketing strategies tailored to unique conditions within an EM have the potential to transform these issues into opportunities. In particular, firms may need to be ambidextrous and pursue both exploration and exploitation strategies to confront the challenges of dynamic market structures in EMs. For example, a consistent finding across disciplines is the positive impact of exploration strategies such as innovation for organic growth when utilized by incumbent firms [41, 43]. Interestingly, a recent meta-analysis finds that innovation has the most significant and positive impact on organic growth [3]. However, these studies are based on data from HIC markets, in general, individual studies (e.g., [11]).

Evidence, in the literature, on the role of innovation in stimulating growth in EM conditions is mixed. In strategy literature, the dynamism of the EM context marked by institutional turbulence, complexity, and within-country diversity has been shown to attenuate and even disrupt implementation of innovation-related programs among domestic firms [57]. However, the impact on MNCs entering EMs has not been as clearly determined. MNCs can generally draw from a greater number of resources and experiences relative to smaller domestic competitors, which can enable them to more easily follow an exploration strategy. Consequently, we expect that an exploration strategy can help MNCs mitigate the negative effects of changing market structures by enabling them to better respond to the evolving needs in the retail, category, and competitive structures. In particular, the growth of modern trade can enable market expansion when firms are able to innovate at the right pace and take advantage of the growing demand for products that accompanies the emergence of formal competition among modern trade outlets. Innovative firm offerings also enable a firm to compete against organized retailers' private-label products [31], which are often a corollary for the development of modern trade retailers. In addition, recent research finds that consumers in low socioeconomic levels have demonstrated higher levels of adoption for modern grocery retailers than the middle-class consumers [39]. Finally, as the growing purchasing power within EMs enables more people to become consumers of commercial products, firms that create new offerings to meet the unique needs of these consumers will be better positioned to grow relative to firms that attempt to sell existing products. In essence, we argue that the intensity of product innovation can mitigate the effect of competitive intensity by enabling firms to adjust, change, and respond to competitive offerings. Consistently, Bahadir et al. [4] find innovation to have twice as much the effect on brand sales in emerging markets vs. in developed markets. Therefore,
H2. The greater the use of exploration strategies, the lower the negative effect of (a) the share of modern retail trade on firm performance, (b) category dynamism on firm performance, and (c) competitive intensity on firm performance.

We contend that, in addition to exploration investments, firms also use exploitation strategies in EMs. Exploitation strategies include investments that enhance the affordability, availability, or acceptability of existing products. Investments in acceptability focus on generating consumer demand via advertising and consumer promotions; investments in affordability (e.g., price) and availability (e.g., distribution) enable the commercialization and sales of products in the retail environment. Both the business press and recent conceptual literature suggest that strategies aimed at availability and affordability are more effective in EM conditions (e.g., [50]); however, empirical evidence for this claim is limited. Bahadir et al. [4] find that distribution has a significantly greater positive elasticity on brand sales in emerging markets over developed markets; however, they also find that price has a significantly greater negative effect on brand sales in developed markets vs. emerging markets.

The importance of availability and affordability is based on the nature of consumer behavior in EM conditions; despite economic growth, many EM consumers still live on low wages relative to HIC standards and therefore are more driven by resource constraints [50]. Marketing resources, targeted at availability and affordability, also lower costs for retailers and support their abilities to not only carry but also recommend products to EM consumers that rely on retailer advice [13]. At the same time, even consumers who cannot participate in the formal market have aspirations and preferences for brands and products, which can be realized as their economic situations improve. Thus, in EM conditions, consumer-associated investments, in the form of advertising and promotions, can be an effective means of establishing brand perception; albeit whether such impact may always override the effects of the resource constraints facing consumers is an empirical question. Formally,

H3. The greater the use of exploitation strategies in the form of consumer investments, the lower the negative effect of (a) the share of modern retail trade on firm performance, (b) category dynamism on firm performance, and (c) competitive intensity on firm performance.

H4. The greater the use of exploitation strategies in the form of retail investments, the lower the negative effect of (a) the share of modern retail trade on firm performance, (b) category dynamism on firm performance, and (c) competitive intensity on firm performance. 


\section{Data, Variables, and Empirical Analysis}

\subsection{Study Context}

Studying the dynamic effect of EM conditions and strategic marketing responses by firms requires longitudinal data on both market structure and firm-level marketing investment data. It is very challenging to access the richness and depth of a measure exclusively from secondary sources and multiple firms. As a result, we focused the analysis on one MNC competing in 15 EM countries. While we cannot reveal the name for confidentiality reasons, the firm is a manufacturer of consumer products and has been present in HICs and EMs for decades.

By focusing on one firm, we also benefit from homogeneity across business units with similar product portfolios and business models without confounding the analysis with differences that could exist across industry characteristics, business models, and firm cultures. Managers did report that the business units in our sample have significantly adapted their marketing strategies and programs to local conditions to provide for sufficient variance in terms of organizational behavior and outcomes. However, we also acknowledge the risks to generalizability that a single-firm study poses, particularly if the firm was a recent entrant into EMs. A recent entrant would likely focus on current product offerings and might be less inclined to adopt exploration strategies; in this case, a trade-off between exploration and exploitation, which is of critical interest to our study, would not be observable. Our data come from an MNC with more than 2 decades of experience conducting business in the EMs associated with our sample; this increases the likelihood of the firm adopting both exploration and exploitation strategies.

Another concern with a one-firm study is that the nature of a particular line of business would skew a firm's customer base toward a particular socioeconomic segment that would experience firm-specific responses to variables in the study. For instance, firms selling high-end luxury goods to a high-income segment in an EM may not experience changes caused by evolutions in market structures impacting mass-market products. However, the company in our sample sells products of mass appeal across most socioeconomic market segments. Our assumption is that while the limitations in our data would not make the findings applicable across all industry conditions, we believe that the above would make the findings relevant for consumer product firms selling mass-market products.

\subsection{Measures}

We drew on data from the World Bank when selecting 15 countries to represent the universe of EM conditions in our study and ensure heterogeneity in the sample across geographic locations. The countries represent four continents and included the BRICTS markets (i.e., Brazil, Russia, India, China, Turkey, and South Africa), along with Argentina, Chile,
Colombia, Malaysia, Mexico, the Philippines, Poland, Romania, and Thailand. Together, these countries represent $36 \%$ of the world's GDP in terms of purchasing power parity in 2013 US dollars. The product offerings of the firm in the study are similar across countries, allowing us to control for category heterogeneity when evaluating differences in marketing strategy and market structure.

Market structure was operationalized using three variables. First, retail structure was measured via the share of modern retail relative to total industry retail sales by year. As the share of modern trade increases, it has a transformational change in the structure of the retail industry as consumers begin to purchase less from smaller and more fragmented stores and more from hypermarkets and supermarkets with greater assortments and more attractive pricing. Category structure dynamism was measured via the change in share of sales across different segments within the industry in the study relative to a base level (i.e., 2000). The value of the category structure dynamism measure would be higher if the change of share of sales across product segments increased relative to the share in 2000. For example, high category structure dynamism could describe a product category that was dominated by one product segment in the year 2000; however, by year 2008, the majority of its category sales were distributed among two or more product segments. Finally, competitive intensity is measured using a Herfindahl index (HHI) of concentration of sales by firms in the category [54]; the higher the competitive intensity in the industry, the lower the concentration of sales in the industry among the participating group of companies. Table 1 summarizes the measures used in the study.

The data for all three market dynamism measures was sourced from Euromonitor and covered 9 years from 2000 to 2008. The data on marketing strategies utilized by the business units were provided by the MNC in the study. Exploitation strategy investments are proxied by two variables. Investments by country by year, in advertising and consumer promotions, were categorized as consumer investments in awareness and acceptability. The resources used for retail programs aimed at expanding distribution, merchandising, and pricing in the outlets were categorized as affordability and availability investments. To capture exploration, we used the data provided by the firm on the count of new products introduced in each country (by year) to represent a measure of innovation intensity. In adopting this measure, we follow prior research that used the count of innovation output as a metric of innovation activity [47]. However, we customize the measure to our context by using the count of new products introduced in the market instead of the count of patents awarded to a firm [52]. The reason for this change is that our analysis is focused on market-facing innovation activity instead of the innovation capability of a firm. The dependent variable is sales growth and was measured as the year on year change in unit volume provided by the firm. While a profitability measure would 
Table 1 Variables and measures

\begin{tabular}{lll}
\hline Variable & Data source & Measure \\
\hline Sales growth & Proprietary source & Year on year change in units sold \\
Consumer investments & Proprietary source & $\begin{array}{l}\text { investment per unit allocated to consumer advertising and promotion } \\
\text { investment per unit allocated to retail costs associated with distribution and pricing }\end{array}$ \\
Retail investments & Proprietary source & Count of products added to the product portfolio by year. \\
Innovation intensity & Proprietary source & Share of industry sales for the modern trade \\
Category dynamism & Datamonitor & Change in share of sales by product segment within the industry \\
Competitive intensity & Datamonitor & Sum of square of sales by the top three largest firms in the industry. \\
GDP change & Watamonitor & Year on year change in Gross Domestic Product (GDP) per capita \\
Inflation & World Bank & Consumer Price Index by year \\
Institutional quality & World Bank & Average of six institutional quality dimensions: control of corruption, government \\
& & effectiveness, political stability, regulatory quality, rule of law, voice and accountability \\
\hline
\end{tabular}

have been more appropriate, profit data at the country level was not available. We also utilize this measure as sales growth is highly correlated to operational profits for this firm. Finally, we controlled for change in GDP per capita and inflation by using data on the consumer price index as reported by the United Nations statistics group. Managers from the firm suggested that such macroeconomic factors significantly affected their sales results. We also controlled for institutional quality in each country, as institutions have significant influence on how markets are regulated and operated [1, 50]. Descriptive statistics for the data on the study is found on Table 2. Table 3 presents the contrast on the three market structure dimensions between EM and HIC markets. The comparison shows that EMs demonstrate faster growth rates in share of modern retail trade, greater category dynamism, and greater change industry concentration all of which reflect the greater dynamism of emerging markets.

\subsection{Estimation}

The data from the 15 countries was in a panel format, which allows us to account for unobserved country factors in the

Table 2 Descriptive statistics

\begin{tabular}{lll}
\hline Variable & Mean & Standard deviation \\
\hline Sales growth & .084 & .100 \\
Consumer investment per unit & 2833 & 14673 \\
Retail investment per unit & 2427 & 12180 \\
Product innovation & .160 & .160 \\
Modern retail share & .22 & .127 \\
Category dynamism & .013 & .009 \\
Competitive intensity & .73 & .15 \\
Consumer price index & 7.69 & 9.50 \\
Change in GDP per capita & 0.04 & 0.03 \\
Institutional quality & -0.03 & 0.49 \\
\hline
\end{tabular}

estimation. We specify the following model to test our hypotheses:

(Sales Growth) $)_{i t}=\beta_{0}+\beta_{1}$ (Consumer Investments) ${ }_{i t}+\beta_{2}$ (Retail Investments) $)_{\text {it }}+\beta_{3}$ (Innovation Intensity) $+\beta_{4}$ (Percent of Sales Through Modern retail $)_{\text {it }}+\beta_{5}$ (Category dynamism) $)_{\text {it }}+$ $\beta_{6}$ (Competitive intensity) ${ }_{\mathrm{it}}+\beta_{7}$ (Consumer Investments $\times$ Modern Retail Share $)_{\text {it }}+\beta_{8}$ (Consumer Investments $\times$ Category dynamism $)_{\text {it }}+\beta_{9}$ (Consumer Investments $\times$ Competitive intensity $)_{\mathrm{it}}+\beta_{10}$ (Consumer wealth growth) $)_{\mathrm{it}}+\beta_{11}(\mathrm{CPI})_{\mathrm{it}}+$ $\beta_{12}$ (Institutional Quality) ${ }_{i t}+v_{i}+\varepsilon_{i}$

(Sales Growth) ${ }_{\mathrm{it}}=\beta_{0}+\beta_{1}$ (Consumer Investments) $)_{\mathrm{it}}+\beta_{2}$ (Retail Investments) ${ }_{\text {it }}+\beta_{3}$ (Innovation Intensity) $+\beta_{4}$ (Percent of Sales Through Modern retail $)_{\text {it }}+\beta_{5}$ (Category dynamism) $)_{\text {it }}+$ $\beta_{6}$ (Competitive intensity) ${ }_{i t}+\beta_{7}$ (Retail Investments $\times$ Percent of Sales Through Modern retail) $)_{\mathrm{it}}+\beta_{8}$ (Retail Investments $\times$ Category dynamism) ${ }_{i t}+\beta_{9}$ (Retail Investments $\times$ Competitive intensity $)_{\mathrm{it}}+\beta_{10}$ (Consumer wealth growth) $)_{\mathrm{it}}+\beta_{11}(\mathrm{CPI})_{\mathrm{it}}+$ $\beta_{12}$ (Institutional Quality) $)_{i t}+v_{i}+\varepsilon_{i}$

(Sales Growth) $)_{\mathrm{it}}=\beta_{0}+\beta_{1}$ (Consumer Investments) $)_{\mathrm{it}}+\beta_{2}$ (Retail Investments) $)_{i t}+\beta_{3}$ (Innovation Intensity) $+\beta_{4}$ (Percent of Sales Through Modern retail $)_{\mathrm{it}}+\beta_{5}$ (Category dynamism) ${ }_{\mathrm{it}}+$ $\beta_{6}$ (Competitive intensity) ${ }_{i t}+\beta_{7}$ (Innovation Intensity $x$

Table 3 Comparison of EM with HIC markets on market structure

\begin{tabular}{|c|c|c|}
\hline & $\begin{array}{l}\text { Emerging } \\
\text { markets }\end{array}$ & $\begin{array}{l}\text { High-income } \\
\text { countries }\end{array}$ \\
\hline Growth of modern retail share (growth) & $6.21 \%$ & $0.33 \%$ \\
\hline Category dynamism & 0.013 & 0.0083 \\
\hline Change in competitive intensity & 0.0059 & 0.0048 \\
\hline
\end{tabular}


Percent of Sales Through Modern retail) ${ }_{i t}+\beta_{8}$ (Innovation Intensity $\times$ Category dynamism $)_{\text {it }}+\beta_{9}$ (Innovation Intensity $\times$ Competitive intensity $)_{\mathrm{it}}+\beta_{10}$ (Consumer wealth growth $)_{\mathrm{it}}+$ $\beta_{11}(\mathrm{CPI})_{\mathrm{it}}+\beta_{12}$ (Institutional Quality $)_{\mathrm{it}}+v_{\mathrm{i}}+\varepsilon_{\mathrm{i}}$

In the model specification, it denotes the countries and it represents the years. We use a fixed effect (within) technique to estimate Eqs. 1 to 3. The models assume unobserved country characteristics to be fixed. These fixed effects are removed by subtracting the mean of each variable from the observed values of the variables. Fixed effects require fewer assumptions relative to random effect and between estimators [10]. ${ }^{1}$ We estimate Eqs. 1-3 using data from the sample of EM countries.

\subsection{Results}

As reported in Table 4, the main effects model provides evidence for the negative effect of changes in market structure on firm performance (as stated in $\mathrm{H} 1 \mathrm{a}$ and $\mathrm{H} 1 \mathrm{c}$ ). As expected, growth in modern trade and increases in competitive intensity create challenges that can affect the sales growth of incumbent brands in EMs. While changes in category structure are in the right direction with regard to their expected impact on sales growth, they are not statistically significant; thus, H1b is not supported. It is plausible that EM consumers are willing to try new types of brands and categories due to novelty effects; however, the loyalty or habit associated with the consumption of incumbent brands makes category dynamism a less dominant or slower influence on firm performance.

The second set of hypotheses is associated with exploration and exploitation marketing strategies utilized by firms in EM conditions. Sample size limitations indicated that it would be prudent to run the model with one set of interaction variables at a time due to the sensitivity to sample size and the likelihood of finding support for the interaction hypotheses [36]. In Table 4, we report the results with this analysis. Regarding the main effect of the exploration strategy, measured via innovation intensity, the results suggest that new product introductions can have negative effects on unit sales growth. We believe that this could be due to cannibalization of existing products, which could be, in part, driven by retailers' reluctance to provide additional shelf space for the firms' products. The results for the interaction between

\footnotetext{
${ }^{1}$ In terms of estimation options, we could use a random effects model, which requires the assumption that random error component and country characteristics included in the model are not correlated. Instead, in order to use a more conservative test of the relationships of interest, we use a fixed effects model. Adding time dummies would reduce the degrees of freedom significantly. However, we use three time-varying macro-level variables (change GDP per capita, inflation rate, and institutional quality) that directly or indirectly influence the purchase behavior of consumers in EMs.
}

innovation and modern trade further support this argument. Contrary to our expectation $(\mathrm{H} 2 \mathrm{a})$, we find that there is a negative interaction between innovation intensity and modern trade. This result suggests that the negative impact of modern trade is enhanced when the company introduces new products; this is consistent with arguments supporting retailers' reluctance to allocate more shelf space to new products. In support of $\mathrm{H} 2 \mathrm{c}$, innovation intensity moderates the negative effect of competitive intensity on sales growth.

The exploitation strategy hypotheses were tested via the utilization of measures of consumer and retail investments. No direct or moderating effect could be found between consumer investment strategy and sales growth within EMs in our study. Thus, we do not find support for $\mathrm{H} 3 \mathrm{a}, \mathrm{H} 3 \mathrm{~b}$, and $\mathrm{H} 3 \mathrm{c}$. However, the results of the interaction between consumer strategies and changes in market structure suggest that consumer investment strategies could have a mitigating effect. However, this would not be significant enough to help a firm convert the environmental change into a growth opportunity. Finally, consistent with hypothesis $4 \mathrm{a}, 4 \mathrm{~b}$, and $4 \mathrm{c}$, we find retail investments to moderate the impact of market structure change on sales growth when they are applied to issues of affordability and availability. Specifically, retail investment strategies serve to counter the effect of changes in category, retail, and competitive structures. As a robustness check, we ran the regression model by including both retail and innovation strategy interactions, and the results remain consistent. ${ }^{2}$ Multicollinearity did not appear to be a significant concern with the mean VIF being 7.21.

\section{Discussion and Implications}

\subsection{Summary of Findings}

The literature to date has recognized the unique and distinct conditions that prevent firms from incorporating HIC strategies into their efforts to grow within EMs. As stated by Sheth [50], EMs are highly heterogeneous and present MNCs with unique sets of challenges such as limited infrastructure, resource limitation, regulation uncertainty, and unbranded competition. They also offer a significant opportunity for growth when firms utilize strategies tailored to EMs' unique dynamics. In this study, we build on the description of the unique conditions in EMs by proposing that it is not only the current static state in EMs but also their degree and rate of transformation that requires attention and understanding.

We find that an evolution in market structure inhibits sales growth. This finding is consistent across retail and competitive

\footnotetext{
${ }^{2}$ We did not include consumer investment strategies because none of the interactions were significant. We also wanted to maintain model parsimony.
} 
Table 4 Estimation results

\begin{tabular}{|c|c|c|c|c|c|c|}
\hline Variable & $\begin{array}{l}\text { Exp. } \\
\text { sign }\end{array}$ & Main effects ${ }^{\mathrm{a}}$ & $\begin{array}{l}\text { Consumer } \\
\text { strategy }^{\mathrm{a}}\end{array}$ & Retail strategy $^{\mathrm{a}}$ & $\begin{array}{l}\text { Innovation } \\
\text { strategy }^{\mathrm{a}}\end{array}$ & $\begin{array}{l}\text { Retail and } \\
\text { innovation }\end{array}$ \\
\hline Intercept & & $-.17 * * * /(.10)$ & $-0.07 /(0.09)$ & $-0.12 /(0.09)$ & $-0.04 /(0.07)$ & $-0.09 /(0.08)$ \\
\hline Consumer price index & - & $-0.004 * /(.002)$ & $-0.004 * /(.001)$ & $-0.002 * * * /(.0015)$ & $-0.003^{* * /(.001)}$ & $-0.002 * * *(0.001)$ \\
\hline Change in GDP per capita & + & $0.54 /(0.46)$ & $0.59 /(0.45)$ & $0.62 * * * /(0.37)$ & $0.60 * * * /(0.44)$ & $0.66^{* * /(0.36)}$ \\
\hline Institutional quality & & $-0.09 /(0.10)$ & $-0.10 /(0.11)$ & $-0.09 /(0.11)$ & $-0.09 /(0.11)$ & $-0.08 /(0.11)$ \\
\hline \multicolumn{7}{|l|}{ Market characteristics } \\
\hline Modern retail share & - & $-0.77 * * /(0.38)$ & $-0.76 * /(0.46)$ & $-1.04 * * /(0.48)$ & $-0.56 * * * /(0.36)$ & $-0.83 * * /(0.43)$ \\
\hline Category dynamism & - & $-0.01 /(0.01)$ & $-0.01 /(0.01)$ & $-0.001 /(0.009)$ & $0.001 /(0.01)$ & $-0.01 /(0.01)$ \\
\hline Competitive intensity & - & $-0.51 * * * /(0.14)$ & $-0.59 * /(0.16)$ & $-0.66 * /(0.22)$ & $-0.48 * /(0.17)$ & $-0.56^{*}(0.19)$ \\
\hline \multicolumn{7}{|l|}{ Moderators } \\
\hline Consumer investments & - & $-0.008 /(0.01)$ & $-0.003 /(0.013)$ & $-0.01 /(0.01)$ & $-0.01 /(.01)$ & $-0.009 * * * /(0.007)$ \\
\hline Retail investments & + & $0.01 /(0.01)$ & $0.01 /(0.01)$ & $0.02 * * * /(0.01)$ & $0.01 /(0.01)$ & $0.02 * * * /(0.01)$ \\
\hline Innovation intensity & + & $0.12 * * * /(0.07)$ & $0.13 * /(0.08)$ & $0.14 * * /(0.07)$ & $-0.10 * * /(0.05)$ & $-0.09 * /(0.06)$ \\
\hline \multicolumn{7}{|l|}{ Interactions } \\
\hline Consumer investments $\times$ modern retail share & + & & $0.03 /(0.06)$ & & & \\
\hline Consumer investments $\times$ category dynamism & + & & $0.003 /(0.003)$ & & & \\
\hline Consumer investments $\times$ competitive intensity & + & & $.003 /(0.06)$ & & & \\
\hline Retail investments $\times$ modern retail share & + & & & $0.10 * * /(0.05)$ & & $0.07 * * /(0.03)$ \\
\hline Retail investments $\times$ category dynamism & + & & & $0.008^{* * *} /(0.005)$ & & $0.006 * * * /(0.004)$ \\
\hline Retail investments $\times$ competitive intensity & + & & & $0.15 * * /(0.08)$ & & $0.14 * * /(0.07)$ \\
\hline Innovation intensity $\times$ modern retail share & + & & & & $-0.47 * * * /(0.35)$ & $-0.44 /(0.39)$ \\
\hline Innovation intensity $\times$ category dynamism & + & & & & $0.13 * * /(0.06)$ & $0.13 * * /(0.06)$ \\
\hline Innovation intensity $\times$ competitive intensity & + & & & & $0.66 * /(0.25)$ & $0.65 * * /(0.27)$ \\
\hline$F$ test & & $7.59(.0005)$ & $51.87(.0001)$ & $40.64(.0001)$ & $34.05 /(.0001)$ & $57.66 /(0.001)$ \\
\hline$R^{2}$ & & 0.21 & 0.21 & 0.25 & 0.30 & 0.33 \\
\hline$\Delta R^{2}$ (significance) & & & & $0.04 *$ & $0.09 *$ & $0.12^{*}$ \\
\hline
\end{tabular}

Dependent variable: sales growth

${ }^{a}$ Unstandardized estimate (clustered robust standard error)

${ }^{*} p<0.01$

$* * p<0.05$

$* * * p<0.10$ (one-tailed directional hypothesis)

structures. Our main objective is to understand whether exploitation- and exploration-oriented marketing strategies could mitigate the deleterious impact of market structure dynamics on sales growth. We find that exploitation strategies, via consumer investments, do not mitigate the negative impact of market structure. However, exploitation strategies targeted at retailers help mitigate the negative impact of modern retail growth, category dynamism, and competitive intensity on sales growth. As depicted in Fig. 1, the dysfunctional effect of the growth in modern retail, category dynamism, and competitive intensity decreases as retailer-targeted marketing investment increases; this provides strong support for it acting as a countervailing strategy in EMs. Similarly, Fig. 2 presents the effects of explorationoriented marketing strategy (i.e., innovation) on sales growth performance, conditional on different levels of category dynamism and competitive intensity. As can be seen from the figure, innovation intensity has a progressively mitigating effect on sales growth performance as category dynamism and competitive intensity increase, providing further support for the positive impact of an exploration-oriented marketing strategy. The effect of the macroeconomic control variables is in the expected direction. Increases in prices negatively affect sales growth; increases in consumer wealth positively affect sales growth.

Surprisingly, consumer investments do not mitigate the negative influence of market structure. We suspected that consumer investments build brand equity and thus might have an indirect (vs. a direct) impact on sales growth. Consequently, we conducted some additional analysis (as reported in Table 5). Specifically, we find that consumer strategies (i.e., demand creation) play a role in supporting growth via the construction of 
Fig. 1 Moderating effect of exploitation strategies
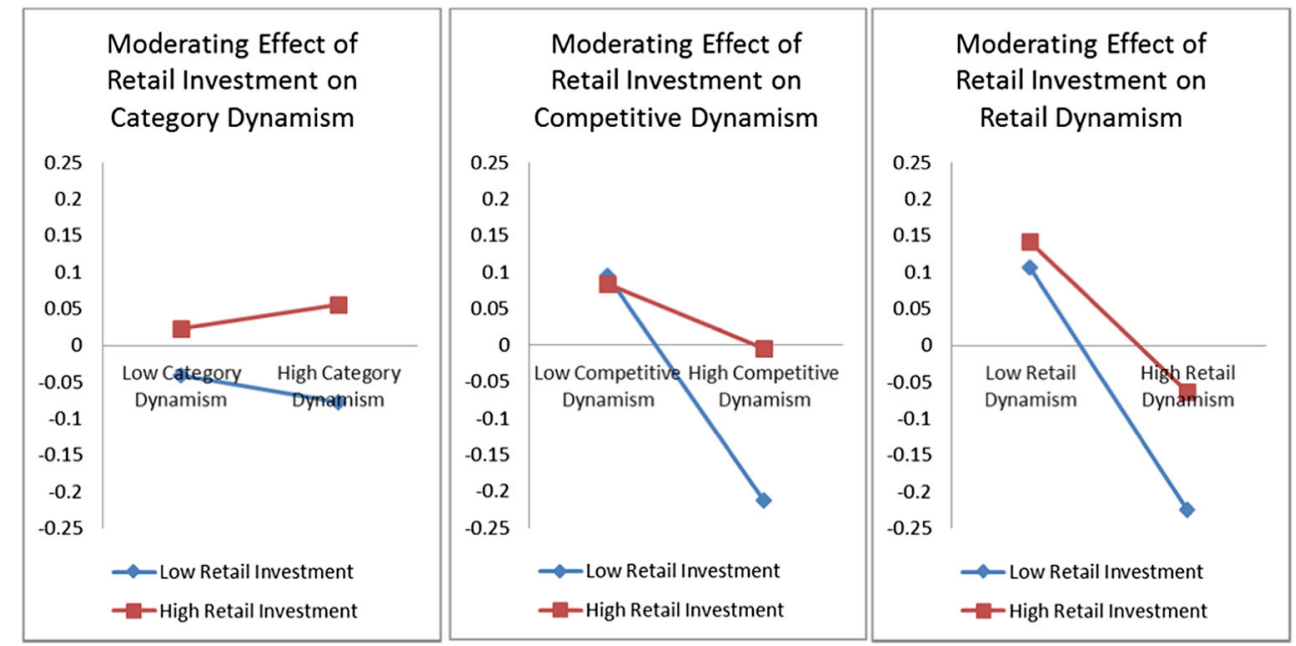

brand equity. As shown in Table 5, consumer investments do lead to a significant increase in brand preference. Therefore, consumer investments may mitigate the negative effects of market dynamics by contributing to brand equity over the long run. However, the indirect effect of consumer investments on sales growth was not significant when tested using the Preacher and Hayes [46] bootstrapping procedure; this indicates that its effect was not mediated via brand preference (the $95 \%$ bootstrap confidence interval was -.0026 to .001 and thus includes zero). Given these results, we contend that brand preference may become a more important influence on sales growth only after other commercial aspects of a marketing mix (e.g., retail penetration and affordability) are established. Therefore, it may be that in EMs, managers should prioritize the development of commercial foundations (associated with their brands) prior to shifting significant resources to branding activities.

\subsection{Research Implications}

Recent reviews of theories of firm performance emphasize the importance of studying the interplay between a business environment and associated firm strategies (e.g., [8]). Relatedly, contingency theory (CT) argues for the need for fit between strategy and the environment in order to deliver superior performance [45, 56, 59]. The findings of this study add new evidence, in an EM context, for the limited empirical CT literature on fit. Consistent with this literature, we find that exploitation- and explorationoriented marketing strategies need to fit the environment in EMs [29]. Our findings provide a more granular understanding of the interaction between marketing strategies and market environment. Innovation intensity, an exploration-oriented marketing strategy, and retail investments, an exploitation-oriented marketing strategy,
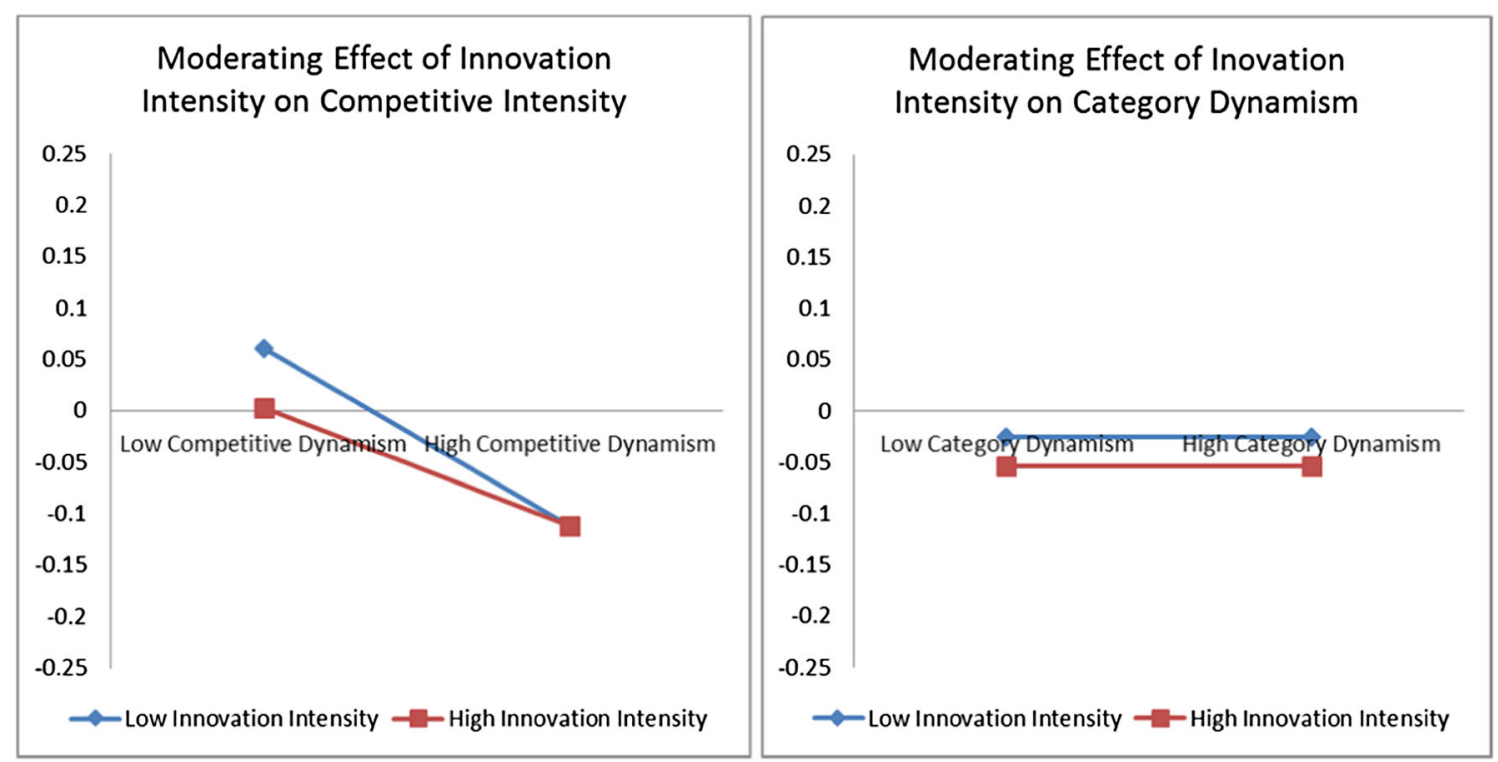

Fig. 2 Moderating effect of exploration strategy 
Table 5 Additional analysis: brand preference as a dependent variable

$\begin{array}{ll}\text { DV: brand preference } & \\ \text { Variable } & \begin{array}{c}\text { Unstandardized estimate } \\ \text { (clustered robust } \\ \text { standard error) }\end{array} \\ & 0.21^{*}(.11) \\ \text { Intercept } & \\ \text { Controls } & 0.0004(0.0008) \\ \text { Consumer price index } & -0.10(0.23) \\ \text { Consumer wealth } & 0.002(0.035) \\ \text { Political governance } & \\ \text { Market characteristics } & 0.11(0.22) \\ \text { Modern retail share } & -0.36(0.46) \\ \text { Category dynamism } & -0.22 * *(0.14) \\ \text { Competitive intensity } & \\ \text { Firm } & 0.004 *(0.002) \\ \text { Consumer investment } & -0.003(0.002) \\ \text { Retail investment } & 0.021 * *(0.011) \\ \text { Innovation intensity } & 27.58(0.0001) \\ \text { F Test } & \end{array}$

The measure, brand equity, is based on consumer survey studies conducted by a third-party company; a representative sample of consumers is asked questions about perception of the brand's attributes and value

${ }^{*} p<0.01$

$* * p<0.05$

emerge as significant moderators of the negative effect created in the context of our study (i.e., the market environment in EMs).

This finding also indicates the importance of ambidextrous capability. While retailer-targeted exploitation strategies enable a firm to counter environmental constraints, exploration-oriented marketing strategies help it to reduce the negative effect of competitive and category dynamism. The results thus provide empirical support for the research on ambidextrous strategies, which focus on the abilities of organizations to simultaneously deal with paradoxical or conflicting activities such as organizational alignment and adaptation, evolutionary and revolutionary change, and exploratory and exploitative strategies $[19,21,55]$. While ambidextrous strategies are challenging, they can generate significant sales growth benefits when executed well, and they can be difficult for competitors to counter or emulate.

The findings on retailer-oriented (i.e., exploitation) marketing strategies also contribute to the emerging literature on shopper marketing [35]. Shopper marketing is perceived to be increasingly important in HIC markets. Our results suggest that even in EMs, brand managers can collaborate and create joint strategies to engage consumers and encourage sales growth. A relevant future research initiative could include the study of the complementarity of exploration and exploitation strategies in EM conditions.

\subsection{Managerial Implications}

Our findings provide managerial insights associated with marketing strategies in EMs. Sales growth is a critical performance metric that is highly valued by the investment community. Pressures on sales growth in developed HIC markets have motivated many firms to enter EMs. A key implication for brand managers is that they can focus on innovation and retail investments to attain higher sales growth in dynamic EMs; these two strategies are effective in dealing with the deleterious effects of retailer scale, category dynamism, and competitive intensity on sales growth. Also, the development of new products, specifically for EMs, has a direct and enhancing impact on sales growth and a mitigating impact on market dynamism. Thus, brand managers can counter the competitive threats from unbranded products (e.g., [50]) by differentiating their products through innovation. Sustaining a focus on the innovation of products, unique to dynamic EMs, may enable firms to deliver and leverage growth opportunities that are not available in developed markets. Our analysis seems to provide, at a macro-level, support for anecdotes in the business press of successful innovations that are uniquely developed for EMs.

Our findings also clarify the importance of exploitation-oriented strategies (i.e., retail investments) in EMs. While many EMs are dominated by small retail outlets, large and modern retailers are becoming increasingly commonplace as well as their adoption by consumers. Brand managers can counter the bargaining power of these large, modern retailers by building stronger relationships with retailers via investments in their retailer-focused strategies. For the category and firm we are analyzing, retailers provide important channels for reaching consumers. This holds true in both HICs and EMs; however, retailers probably have greater power in EMs because distribution is the most important element of a marketing mix in EMs [4]. Thus, for innovations to be effective in EMs, they must be very closely coordinated with retailers. Otherwise, new product introductions can hurt sales growth via cannibalization. Cannibalization is due to the fixed shelf allocation implemented by retailers.

Similar to innovation, retail-oriented marketing strategies have a mitigating impact on the power of modern retail, category market dynamism, and competitive intensity. Therefore, managers would benefit from allocating resources to both of these strategies. Finally, we would like to emphasize that managers should also be cognizant of the benefits of consumer investments. While these investments may not pay off immediately, they are extremely important when building brand equity over the long term. 


\section{Limitations and Future Directions}

This study is not without limitations. While we studied 15 EMs and controlled for fixed effects, the heterogeneity in these markets could have been better studied. The limited dataset prevented us from developing country-specific estimates. With additional data, we could have gone beyond associations to address causality directly. The inability to broadly generalize from this study is another limitation. While we do test our model across 15 countries and four continents, we were limited in the number of categories studied; future research could broaden this number of categories. Moreover, we are limited to a single MNC for the data, which limits generalizability to consumer product industries.

Due to limitations in data accessibility, we were unable to explore the effect of exploration and exploitation on other important measures of firm performance, particularly profitability. Despite the positive effect of both strategies on helping firms manage the dynamism of EMs, it is possible that their impact would differ when considering profit as an outcome. This becomes an important outcome to explore in future studies. In addition, the lack of effectiveness of consumer investments in the form of advertising and promotions is unexpected. While we recognize that the findings may be driven by idiosyncratic factors in our data, it is also possible that the results indicate the importance of availability and affordability tactics when designing market exploitation strategies for EMs. If this pattern is found in other industries, it could call into question the value of advertising and promotions as a way of driving growth in dynamic EMs.

\section{References}

1. Acemoglu D, Robinson J (2012) Why nations fail. Crown Business, New York

2. Arragón-Correa JA, Sharma S (2003) A contingent resource-based view of proactive corporate environmental strategy. Acad Manag Rev 28:71-88

3. Bahadir SC, Bharadwaj S, Parzen M (2009) A meta-analysis of the determinants of organic sales growth. Int J Res Mark 26(4):263275

4. Bahadir SC, Bharadwaj SG, Srivastava RK (2015) Marketing mix and global brand sales: examining the contingent role of countrymarket characteristics, forthcoming at J Int Bus Stud doi:10.1057/ jibs.2014.69

5. Bain J (1972) Essays in price theory and industrial organization. Little Brown and Company, Boston

6. Baum JR, Wally S (2003) Strategic decision speed and firm performance. Strateg Manag J 24:1107-1129

7. Bettis RA, Hitt MA (1995) The new competitive landscape. Strateg Manag J 16(Special Issue):7-19

8. Bharadwaj SG, Varadarajan PR (2004) Towards an integrated model of business performance, in Review of Marketing. M.E. Sharpe, Armonk
9. Burgess SM, Steenkamp J-BEM (2006) Marketing renaissance: how research in emerging markets advances marketing science and practice. Int J Res Mark 23:337-356

10. Cameron CA, Trivedi P (2009) Microeconometrics using Stata. Stata Press, College Station

11. Deshpandé R, Farley JU (2004) Organizational culture, market orientation, innovativeness, and firm performance: an international research odyssey. Int J Res Mark 21(1):3-22

12. Dhar SK, Hoch SJ (1997) Why store brand penetration varies by retailer. Mark Sci 16(3):208-227

13. Diaz A, Lacayo J, Salcedo L (2007) Selling to 'mom and pop' stores in emerging markets. Mckinsey Q, Special Edition, 71-81

14. Dobbs R, Reemes J, Smith S (2011) The world's new growth frontier: midsize cities in emerging markets. McKinsey Q 2:46-49

15. Dubé J-P, Hitsch GJ, Rossi PE, Vitorino MA (2008) Category pricing with state-dependent utility. Mark Sci 27(3):417-429

16. Erdem T, Keane MP, Sun B (2008) A dynamic model of brand choice when price and advertising signal product quality. Mark Sci 27(6):1111-1125

17. Erdem T, Swait J, Valenzuela A (2006) Brands as signals: a crosscountry validation study. J Mark 70(1):34-49

18. Farley J, Lehmann D (1994) Cross-national 'Laws' and differences in market response. Manag Sci 40(1):111-122

19. Gibson CB, Birkinshaw J (2004) The antecedents, consequences, and mediating role of organizational ambidexterity. Acad Manag J 47(2):209-218

20. Guillen M, García-Canal E (2012) Emerging markets rule: growth strategies of the new global giants. McGraw Hill Professional

21. He Z-L, Wong P-K (2004) Exploration vs. exploitation: an empirical test of the ambidexterity hypothesis. Organ Sci 15(4):481-491

22. Howe A (2010) Making the leap into emerging markets: an interview with Clorox's Beth Springer, Mckinsey Q, September, 1-6

23. Immelt J, Govindarajan V, Tremble C (2009) How GE is disrupting itself. Harvard Business Review, October, 3-11

24. Ireland RD, Hitt MA, Sirmon DG (2003) A model of strategic entrepreneurship: the construct and its dimensions. J Manag 29(6):963-989

25. Iyengar S, Lepper M (2000) When choice is demotivating: can one desire too much of a good thing? J Pers Soc Psychol 79:995-1006

26. Iyengar S, Lepper M (2002) Choice and its consequences: on the costs and benefits of self-determination. In Tesser A (ed) Self and motivation: emerging psychological perspectives, 71-96. Washington D.C.: American Psychological Association

27. Jain S (1989) Standardization of international marketing strategy: some research hypotheses. J Mark 53(1):70-79

28. Kapferer JN (2008) The new strategic brand management, 4th edn. Kogan, London

29. Katsikeas CS, Samiee S, Theodosiou M (2006) Strategy fit and performance consequences of international marketing standardization. Strateg Manag J 27(9):867-890

30. Kim D-J, Kogut B (1996) Technological platforms and diversification. Organ Sci 7(3):283-301

31. Kumar N, Steenkamp J-BEM (2007) Private label strategy. Harvard Business School Press, Cambridge

32. Levitt T (1983) The globalization of markets. Harv Bus Rev 61(May/June):92-102

33. Lim LKS, Acito F, Rusetski A (2006) Development of archetypes of international marketing strategy. J Int Bus Stud 37:499-524

34. March JG (1991) Exploration and exploitation in organizational learning. Organ Sci 2(1):71-87

35. Marketing Science Institute Report. (2009). Shopper marketing roundtable summary Notes

36. McClelland GH, Judd CM (1993) Statistical difficulties of detecting interactions and moderator effects. Psychol Bull 114(2):376-390

37. Messinger PR, Narasimhan C (1995) Has power shifted in the grocery channel? Mark Sci 14(2):189-223 
38. Mishina Y, Pollock TG, Porac JF (2004) Are more resources always better for growth? Resource stickiness in market and product expansion. Strateg Manag J 25(12):1179-1197

39. Narayan V, Rao V, Sudhir K (2015) Early adoption of modern grocery retail in an emerging market: evidence from India. Forthcoming Marketing Science

40. Neff J (1999) P\&G and Unilever's giant headaches'. Advert Age 70:22-28

41. Odagiri H (1983) R\&D expenditures, royalty payments, and sales growth in Japanese manufacturing corporations. J Ind Econ 32(1): $61-71$

42. Ohmae K (1985) Triad power: the coming shape of global competition. The Free Press, New York

43. Park SH, Luo Y (2001) Guanxi and organizational dynamics: organizational networking in Chinese firms. Strateg Manag J 22(5): 455-476

44. Porter ME (1980) Competitive strategy. Free Press, New York

45. Porter ME (1996) What is strategy? Harv Bus Rev 74(6):61

46. Preacher KJ, Hayes AF (2008) Asymptotic and resampling strategies for assessing and comparing indirect effects in multiple mediator models. Behav Res Methods 40(3):879-891

47. Rothaermel FT, Hess AM (2007) Building dynamic capabilities: innovation driven by individual, firm, and network-level effects. Organ Sci 18:898-921

48. Ryans JK, Griffith DA, White S (2003) Standardization/adaptation of international marketing strategy: necessary conditions for the advancement of knowledge. Int Mark Rev 20:588-603

49. Shafir E, Simonson I, Tversky A (1993) Reason based choice. Cognition 49:11-36

50. Sheth JN (2011) Impact of emerging markets on marketing: rethinking existing perspectives and practices. J Mark 75(4):166-182
51. Sirmon DG, Hitt MA, Ireland RD (2007) Managing firms resources in dynamic environments to create value: looking inside the black box. Acad Manag Rev 32(1):273-292

52. Sorescu A, Spanjol J (2008) Innovation's effect on firm value and risk: insights from consumer packaged goods. J Mark 72(2):114 132

53. Steenkamp JBEM, Batra R, Alden DL (2003) How perceived brand globalness creates brand value. J Int Bus Stud 34(1):53-65

54. Szymanski DM, Bharadwaj SG, Varadarajan P (1993) An analysis of the market share- profitability relationship. J Mark 57(July):118

55. Tushman ML, O'Reilly CA III (1996) Ambidextrous organizations: managing evolutionary and revolutionary change. Calif Manag Rev 38(4):8-30

56. Venkatraman N (1989) The concept of fit in strategy research: toward verbal and statistical correspondence. Acad Manag Rev 14(3): 423-431

57. Wright M, Filatotchev I, Hoskisson RE, Peng MW (2005) Strategy research in emerging economies: challenging the conventional wisdom. J Manag Stud 42(1):1-33

58. Wrigley N, Lowe M (2010). The globalization of trade in retail services. In Report commissioned by the OECD Trade Policy Linkages and Services Division for the OECD Experts Meeting on Distribution Services, Paris, November (Vol. 17)

59. Zajac EJ, Kraatz MS, Bresser RKF (2000) Modeling the dynamics of strategic fit: a normative approach to strategic change. Strateg Manag J 21(4):429-441

60. Zou S, Cavusgil T (2002) The GMS: a broad conceptualization of global marketing strategy and its effect on firm performance. J Mark 66(4):40-56 